\title{
GOVERNANÇA DO RISCO E PRESERVAÇÃO AMBIENTAL EM CONSTRUÇÕES DE USINAS HIDRELÉTRICAS
}

\author{
Ricardo Vilarim David ${ }^{1}$ \\ Universidade Federal de Rondônia \\ ricardo.vilarim@unir.br \\ Pablo Mendonça Siqueira ${ }^{2}$ \\ Universidade Federal de Rondônia \\ pablomendoncasiqueira@gmail.com \\ Mariluce Paes-de-Souza ${ }^{3}$ \\ Universidade Federal de Rondônia \\ mariluce@unir.br \\ Tomás Daniel Menendez Rodriguez ${ }^{4}$ \\ Universidade Federal de Rondônia \\ tomas@unir.br \\ Maria Clarice Alves da Costa ${ }^{5}$ \\ Universidade Federal de Rondônia \\ mariaclaricecosta@hotmail.com \\ Guilherme Giacon da Silva ${ }^{6}$ \\ Universidade Federal de Rondônia \\ guilhermegiacon@hotmail.com
}

\begin{abstract}
Resumo
A pesquisa busca analisar os mecanismos de governança do risco a partir dos elementos e aspectos transversais do framework elaborado pelo Comitê Internacional de Gestão de Riscos (IRGC), com objetivo de identificar ocorrências de mecanismos de governança e preservação ambiental em construções de usinas hidrelétricas. Para tanto, foram realizadas buscas em artigos, previamente selecionados, por meio de revisão sistemática com a utilização do protocolo Thorpe. Devido a esse método de seleção, a pesquisa limitou-se a algumas regiões geográficas, como alguns países do sudeste asiático, do continente africano, além de Brasil e Turquia. O estudo observou que na maioria dos artigos avaliados não foram encontrados os mecanismos de governança do risco, o que evidencia uma lacuna entre as propostas dos projetos e suas execuções. Essa falha indica uma falta de avaliação de possíveis danos às populações afetadas pelas construções. Por fim, conclui-se que é fundamental a utilização da governança do risco na proposição de projetos de usinas hidrelétricas a fim de mitigar os impactos aos habitantes das regiões afetadas pelas construções.
\end{abstract}

Palavras-chave: Governança do Risco. Usinas Hidrelétricas. População Local.

1 Analista de TI, mestrando em Administração pela Universidade Federal de Rondônia (UNIR).

2 Economista, mestrando em Administração pela Universidade Federal de Rondônia (UNIR).

3 Administradora, pós-doutorado em Administração pela Universidade Federal do Rio Grande do Sul (UFRGS). Professora titular da Universidade Federal de Rondônia (UNIR).

4 Matemático, Pós-Doutorado em Matemáticas na Associação Instituto de Matemática Pura e Aplicada - IMPA. Professor titular da Universidade Federal de Rondônia (UNIR).

5 Administradora, mestranda em Administração pela Universidade Federal de Rondônia (UNIR).

6 Econmista, mestrando em Administração pela Universidade Federal de Rondônia (UNIR). 


\title{
RISK GOVERNANCE AND ENVIRONMENTAL PRESERVATION IN HYDROELECTRIC PLANT CONSTRUCTION
}

\begin{abstract}
The research seeks to analyze the risk governance mechanisms based on the elements and transversal aspects of the framework developed by the International Risk Management Committee (IRGC), with the objective of identifying occurrences of governance and environmental preservation mechanisms in hydroelectric power plant construction. For that, searches were carried out on previously selected articles, through systematic review using the Thorpe protocol. Due to this selection method, the research was limited to some geographical regions, such as some countries in Southeast Asia, the African continent, in addition to Brazil and Turkey. The study noted that in most of the articles evaluated, risk governance mechanisms were not found, which highlights a gap between the project proposals and their execution. This failure indicates a lack of assessment of possible damage to the populations affected by the constructions. Finally, it is concluded that it is essential to use risk governance in proposing hydroelectric power plant projects in order to mitigate the impacts on the inhabitants of the regions affected by the constructions.
\end{abstract}

Keywords: Risk Governance. Hydroelectric plants. Local population. 


\section{INTRODUÇÃO}

O debate sobre variações de matrizes energéticas ganhou notoriedade a partir da primeira crise petrolífera ocorrida na década de 1970, esta influência gerou outros debates e algumas “ondas”, conforme relatado por Elkington (2004). Uma onda de legislação ambiental abrangeu toda a área da Organização para Cooperação e Desenvolvimento Econômico (OCDE), além de colocar a indústria em conformidade com o tema. Com o apelo ambiental e uma crise financeira devido ao petróleo, os debates se intensificaram e alguns países passaram a adotar com maior frequência matrizes energéticas não só independentes do petróleo, mas que também demonstrassem causar menor danos ao meio-ambiente do que as tradicionais fósseis.

Alguns países começaram a adotar matrizes diferenciadas, como no caso das usinas nucleares, conforme relatório da IAEA - International Atomic Energy Agency (2018), em que durante os anos 1986 - 1990, aproximadamente 16 países realizaram a construção de usinas nucleares, dentro os quais podemos destacar os Estados Unidos com 22 reatores e a Ucrânia Soviética com 6. Neste mesmo período as usinas hidrelétricas voltaram a ganhar notoriedade nos debates globais a respeito de energia renováveis, "não-poluentes" e que impactassem "menos" a vida humana.

A intervenção humana nos rios não é algo recente na história, neste sentido Hohensinner et al. (2005) abordam que as intervenções no rio Danúbio iniciaram ainda no século XIX, e a construção de uma usina hidrelétrica neste rio foi iniciada ainda na década de 1950. Ainda segundo os mesmos autores, alguns países entendem que a intervenção por meio deste tipo de usina pode trazer mais malefícios do que benefícios para as populações locais, bem como o meio-ambiente da região onde são construídas tais plantas energéticas.

Entretanto, alguns países ainda destinam recursos para a implementação e melhoramento deste tipo de matriz. Conforme Kim, Park e Kim (2017), esses países têm atuado de forma para a expansão do mercado de energias renováveis, trabalhando de forma a atrair investidores externos, seja por meio de incentivos fiscais, políticas público-privadas ou outros tipos de programas. Este mercado de energia renovável criou um boom na indústria energética, principalmente nos países situados na Ásia, África e América do sul.

Neste contexto, a construção de usinas hidrelétricas poderia ser considerada a verdadeira vilã das regiões impactadas ou este motivo poderia se justificar pela forma como são construídas, os seus fins e para quem irão de fato beneficiar diretamente. Compartilhando deste pensamento, o conceito de governança definida como a estrutura que abarca os processos de 
direção e controle (VIEIRA; BARRETO, 2019), pode se tornar um aliado no estudo e análise para resolução de conflitos locais ou também ser utilizada como uma estratégia para mitigar danos inevitáveis. Portanto, existem riscos na construção de empreendimentos como as usinas hidrelétricas, os quais podem ser analisados.

A definição do risco no processo de governança representa uma incerteza em relação às consequências negativas de uma atividade ou evento que possui determinado valor para os seres humanos (LOUZADA; RAVENA, 2018). A governança do risco envolve argumentos relacionados às representações de diferentes grupos sociais, todos os atores sociais passam a ter poder, devido à formulação em conjunto de discurso para enfrentar o problema, compreensão da magnitude do risco, incluindo as diferentes proposições de gerenciamento de riscos, somados a possibilidade de realizar fóruns de discussão no processo de tomada de decisão, através de realização de debates entre os tomadores de decisão e os que executam a decisão em nível político (REN, 2008).

Embora regulamentos de segurança de barragens bem desenvolvidos sejam importantes para gerenciar os riscos relacionados a construção de usinas hidrelétricas, o envolvimento de grupos sociais relevantes é de suma importância para a governança do risco (LOUZADA; RAVENA, 2018). No entanto, ocorrem situações negativas às populações que são afetadas pelas construções de usinas hidrelétricas, conforme afirmam Jumani et al. (2017), em que no caso indiano, tomou tamanha proporção de impacto negativo, que até mesmo causou um desequilíbrio nas interações entre homens e elefantes o que fez os habitantes da região a reverem o custo-benefício da usina implantada.

Desta maneira, esta pesquisa tem como objetivo avaliar os elementos da governança do risco na construção de usinas hidrelétricas, a partir de estudos de revisão sistemática preliminar sobre a temática e responder a seguinte indagação: quais são os elementos e aspectos da governança do risco considerados na construção de usinas hidrelétricas?

Concomitante a construção de usinas hidrelétricas, resultam impactos sociais, econômicos e ambientais para a região do seu entorno, bem como a toda região afetada, motivo pelo qual, dar atenção e observar os riscos e impactos desses projetos é de suma importância. As populações locais devem ser consideradas, além do mero objetivo econômico de tais projetos. O impacto social precisa ser considerado e mitigado, e para isso, a política de riscos precisa ser objetiva e compartilhada por toda a população do local. 


\section{REVISÃO DE LITERATURA}

\subsection{GOVERNANÇA}

Governança significa regras, processos e comportamentos que interferem na forma de execução dos poderes, sobretudo no que tange à abertura, participação, eficiência, coerência e responsabilidade presentes no processo decisório (JASANOFF; MARTELLO, 2004). A governança almeja capturar situações onde o que está em jogo é a coordenação entre atores interdependentes, de forma a lidar com as questões da ação coletiva e da cooperação (GUIMARÃES; MARTIN, 2001).

Quadro 1 - Tipologia dos modos de governança

\begin{tabular}{|c|c|c|c|}
\hline & Hierarquias & Mercados & Redes \\
\hline $\begin{array}{c}\text { Governança } \\
\text { memão entre }\end{array}$ & autoridade & preços & confiança \\
\hline $\begin{array}{c}\text { Grau de } \\
\text { dependego } \\
\text { membia entre }\end{array}$ & dependente & independente & interdependente \\
\hline $\begin{array}{c}\text { Meios de } \\
\text { resolução } \\
\text { de conflito e } \\
\text { coordenação }\end{array}$ & regras e & barganha & diplomacia \\
\hline $\begin{array}{c}\text { Cultura } \\
\text { comandos }\end{array}$ & subordinação & competição & reciprocidade \\
\hline
\end{tabular}

Fonte: Bevir (2012, p.17).

Segundo Vieira e Barreto (2019) “A governança está relacionada a quaisquer processos de coordenação social, razão pela qual não se limita à forma hierárquica e verticalizada, baseada no controle direto e formal, típico do governo do Estado. “. Esta não se confunde ou se restringe ao governo, ela é o processo de direção e controle que ocorre quando o governo dirige politicamente o Estado, assim como quando as empresas dirigem seus empregados ou os parceiros de uma rede fixam regras de deliberação e implementação de suas decisões (RHODES, 1996).

O quadro 1 expõe os três tipos de modos de governança caracterizando-os quanto a relação e grau de dependência entre membros, meios de resolução de conflito e cultura. A hierarquia é o modo de coordenação social com base na autoridade e no controle centralizado. O mercado é o modo baseado nos preços e na competição. A rede é o modo baseado na confiança estabelecida entre parceiros. 
Em suma todos os modos de governança apresentam vantagens e desvantagens, devido a isto, normalmente esses tipos ideais são combinados para maximizar o desempenho e a conformidade dos sistemas em face de seus objetivos. O modo hierarquias tendem à burocratização, tornando-se sistemas rígidos e ineficientes que de forma irresponsiva ao público externo da organização (clientes ou cidadãos) passa a centrar-se em seus próprios processos internos. O modo mercados apresentam limitações que impactam negativamente no sistema de preços, como os monopólios (controle da oferta de um bem por um ou poucos vendedores que operam em cartel), as externalidades (efeito indireto das trocas sobre terceiros), os custos de transação (informação, negociação e garantia dos contratos) que precisam ser devidamente regulados para a efetiva realização dos benefícios de um sistema competitivo de trocas.

Por fim o modo redes necessita de estabilidade e de mecanismos efetivos de sanção ao oportunismo (vínculos contratuais ou de autoridade formal), dificultam o processo de responsabilização ao tornar menos transparente a responsabilidade de cada ator, contribuindo também para a rigidez, inibindo a inovação e a adaptação, em razão da interdependência complexa estabelecida entre múltiplos parceiros.

As decisões sobre o modo, ou a combinação de modos, de governança mais adequado dependem das características e propósitos dos sistemas a serem governados, podendo ser reconhecida a priori uma diferença entre a governança corporativa e a governa pública.

A governança corporativa é o sistema pelo qual as sociedades são dirigidas e controladas, com objetivo de promover valor aos proprietários ou partes interessadas garantindo a sua sustentabilidade. Esta compreende a garantia dos direitos das partes proprietárias e interessadas, a estrutura de poder e de relações entre seus órgãos e o sistema normativo que rege as relações internas e externas das sociedades, além de está centrada nos processos de direção e controle das organizações, abordando a distribuição de direitos e responsabilidades entre seus integrantes, as regras e procedimentos para tomada de decisão e a definição dos meios para alcançar os objetivos e os instrumentos para controlar o desempenho (VIEIRA; BARRETO, 2019).

A governança pública equivale aos processos por meio dos quais os atores sociais interagem para estabelecer padrões de coordenação social, responsáveis pelas estruturas de cooperação social necessárias para resolver os problemas públicos complexos do Estado. Esta estabelece os mecanismos de recompensa facilitando a cooperação, o monitoramento das ações, a disseminação de informações, o incentivo à reciprocidade caracterizada a partir da confiança e realização das sanções para coibir o oportunismo criando condições para a ação coletiva. Uma governança pública consistente garante um quadro de referência institucional que apoia os 


\section{ARTIGO}

INOVAÇÃO

indivíduos a cooperar com as iniciativas de resolução dos problemas públicos do Estado por meio da produção e gestão eficiente dos recursos comuns e dos serviços de interesse público (HOLAHAN; LUBELL, 2016).

\subsection{GOVERNANÇA DO RISCO}

O conceito de governança do risco parte da ideia de um processo decisório democrático e participativo relacionado ao gerenciamento do risco, entendendo participação como o compartilhamento do poder decisório do Estado em relação às questões relativas ao interesse público (DAGNINO; OLVERA; PANFICHI, 2006). Busca-se assegurar que as instituições governamentais atuem de forma responsável perante seus cidadãos, criando possibilidades para que indivíduos e grupos influenciem as decisões que os afetam, contribuindo para a estabilidade do sistema democrático (ASHFORD; REST, 1999).

Renn (2008) define a governança do risco como um processo que engloba representantes de grupos sociais distintos (stakeholders, público diretamente afetado, público observador, autoridades, agências reguladoras). Se faz necessário que estes atores de todos os grupos sociais participem ativamente e construtivamente no discurso para que alcancem uma compreensão e objetivo comum a respeito da magnitude do risco e sobre quais as possíveis formas efetivas para gerenciá-lo (DI GIULIO; FERREIRA, 2013). Justamente por suas características de maior agregação social, é que a governança do risco se faz interessante para ser analisada em regiões em que este tipo de ação não se faz tão presente, no que tange as construções de usinas hidrelétricas. 
Figura 1 - Estrutura de governança do risco do Comitê Internacional de Gestão de Riscos (IRGC)

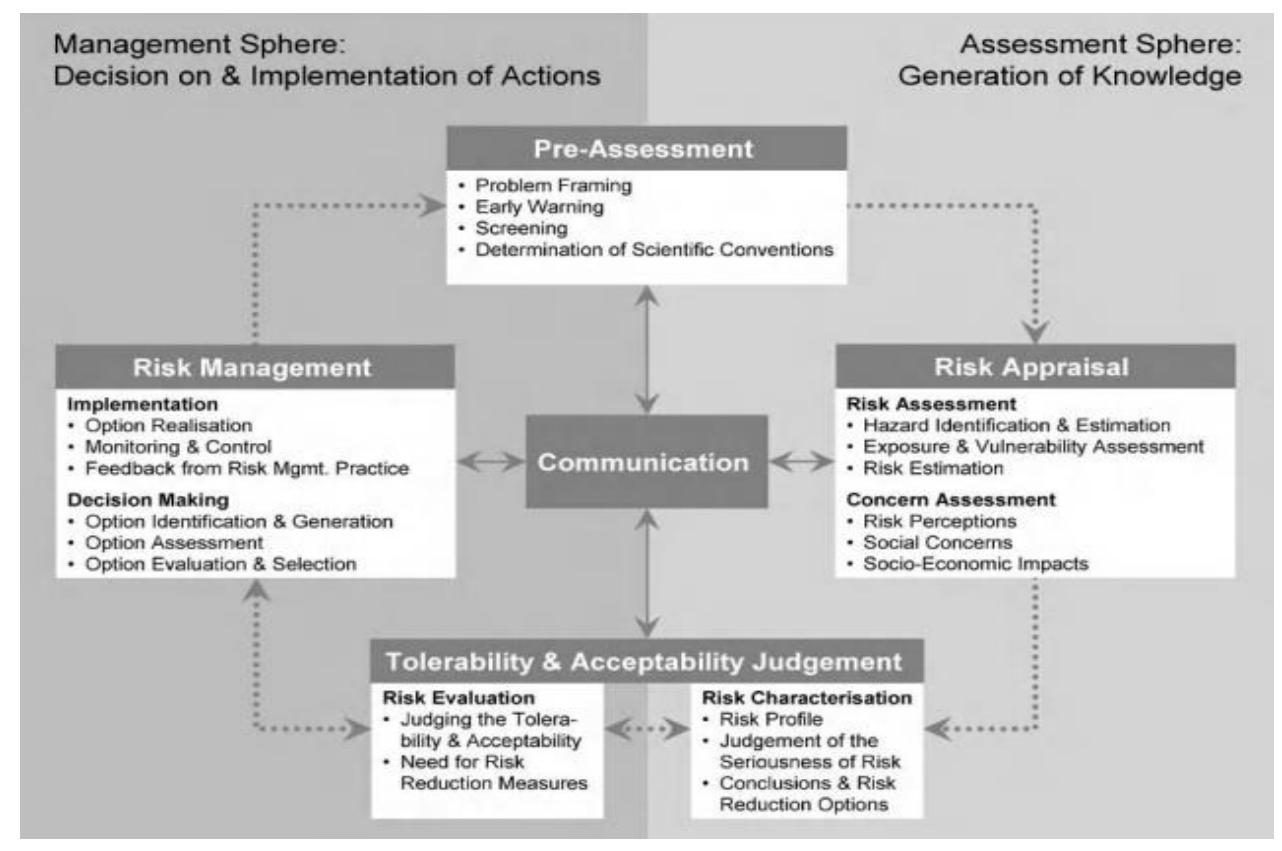

Fonte: Renn e Walker (2008, p. 59).

O Comitê Internacional de Gestão de Riscos (IRGC) desenvolveu uma estrutura abrangente para a governança do risco através da criação de um framework. Este framework possui quatro elementos interligados e três aspectos transversais (figura 1):

- Pré-avaliação - Identificação e enquadramento: leva a estruturar o risco, aviso prévio e preparativos para lidar com ele, envolve atores relevantes e grupos de partes interessadas, de modo a capturar as várias perspectivas sobre o risco, suas oportunidades associadas e possíveis estratégias para enfrentá-lo.

- Avaliação - Avaliação das causas e consequências técnicas percebidas do risco: desenvolve e sintetiza a base de conhecimento para a decisão sobre se um risco deve ou não ser tomado e / ou gerenciado e, se houver, identifica e seleciona quais opções podem estar disponíveis para impedir, mitigar, adaptar ou compartilhar o risco.

- Caracterização e avaliação - Fazendo um julgamento sobre o risco e a necessidade de gerenciá-lo: processo de comparação do resultado da avaliação de riscos (avaliação de riscos e preocupações) com critérios específicos, determina a significância e aceitabilidade do risco e prepara decisões.

- Gerenciamento - Decidir e implementar opções de gerenciamento de riscos: projeta e implementa as ações e soluções necessárias para evitar, reduzir (impedir, adaptar, mitigar), transferir ou reter os riscos. 
- Aspectos transversais - Comunicação, envolvimento com as partes interessadas, considerando o contexto. Existem três aspectos: o papel crucial da comunicação aberta, transparente e inclusiva, a importância de envolver as partes interessadas para avaliar e gerenciar riscos e a necessidade de lidar com o risco de uma maneira que explique totalmente o contexto social, tanto do risco quanto da decisão que será tomada.

A governança do risco envolve um contexto amplo porque inclui identificação, avaliação, gerenciamento e comunicação de riscos, e esse processo deve incluir todos os atores sociais, regras, convenções, processos e mecanismos, além de como as informações relevantes sobre os riscos são coletados, analisados e comunicados e como e por quem as decisões de gestão são tomadas (RENN, 2008, 2016; VAN ASSELT; RENN 2011). A governança do risco introduz um novo modelo de produção de conhecimento e tomada de decisões, porque o envolvimento da comunidade torna possível agir de forma individual ou coletiva para reduzir os riscos e, assim, também se envolver em medidas de mitigação (RENN 2008, 2016; VAN ASSELT; RENN, 2011; DE MARCHI; SCOLOBIG, 2012).

\subsection{CONSTRUÇÃO DE EMPREENDIMENTOS HIDRELÉTRICOS}

Conforme Kim, Park e Kim (2017), o barateamento e o acesso às ferramentas e equipamentos necessários para a instalação de plantas energéticas, devido a evolução tecnológica neste setor, faz com que o mercado de energia renovável se expanda em todo o mundo. Como exemplo, os autores ainda destacam o caso dos países em desenvolvimento, em que o crescimento econômico vinculado a falta de potencial energético, faz com que eles procurem alternativas para sanar tal déficit, sendo uma delas a construção de usinas hidrelétricas. Isso fica evidenciado pelo relatório do REN21 (2019), o qual aponta que países como China, Brasil, Paquistão e Turquia aumentaram suas capacidades em 7 gigawatts, 3.8 gigawatts, 2.5 gigawatts e 1.1 gigawatts respectivamente, somente no ano de 2018.

Para a construção de uma usina hidrelétrica, alguns estágios são considerados para se tomar a decisões de realização, expansão, diminuição ou exclusão. Para atrair o capital de investimento, é necessário que se tenha no projeto as fases de planejamento, design, construção e operação, em que cada uma delas precisa de uma confirmação antes de seguir a posterior. Ainda segundo os autores, na fase de planejamento é analisada principalmente a viabilidade econômica do projeto, considerando principalmente os recursos disponíveis e tempo para realização (KIM; PARK; KIM, 2017). Os autores continuam, após aprovação da primeira fase, 
os investidores passam para a fase do design, em que recebem documentações mais específicas e fazem as avaliações de todo escopo do projeto. Por fim, os autores concluem, que caso sejam realizadas todas as aprovações anteriores, o projeto passa a ser construído e posteriormente operacionalizado, momento quando os investidores passam a receber suas recompensas. A figura 2 , ilustra um esquema das fases mencionadas.

Figura 2 - Esquema de decisão de investimentos em projetos de energias renováveis.

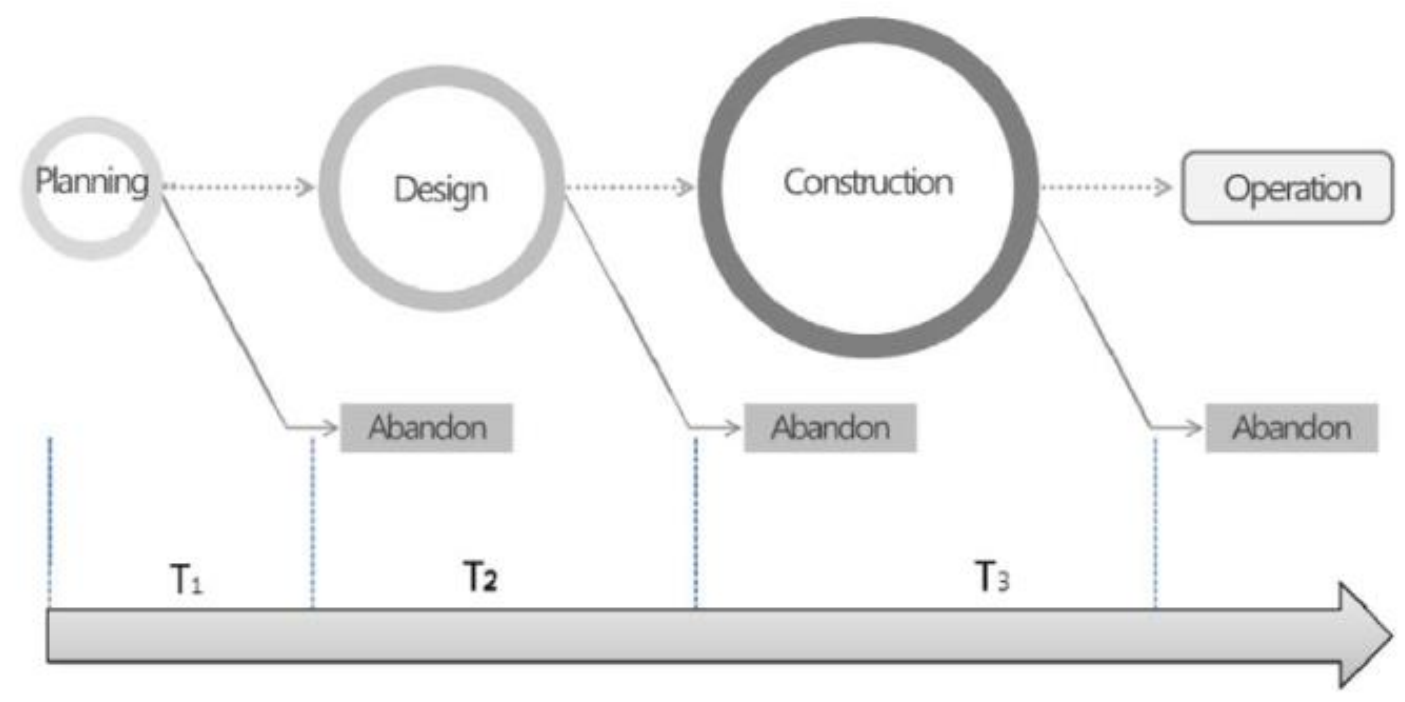

Fonte: Kim, Park e Kim (2017).

Quanto as variáveis em que os investidores analisam, principalmente nas duas fases iniciais, Kim, Park e Kim (2017) destacam as vinculadas aos riscos oriundos de incertezas, visto que eles afetam o fluxo de caixa do projeto. Eles citam, inflação; taxas de juros e cambial; impostos; custos de planejamento, de design, de aquisição, de operação, de seguro e de manutenção; mudanças nas leis locais; decisões políticas; nível produção energética; e período de concessão. Portanto, percebe-se que há uma preocupação majoritariamente financeira na avaliação de projetos hidrelétricos, em detrimento do aspecto socioambiental, conforme destaca Rousseau (2017), em que a vida das populações locais, bem como dos grupos minoritários possuem um peso muito menor na hora de se equalizar um projeto.

Aeria (2016), destaca o plano "Sarawak Corridor of Renewable Energy (SCORE)" de desenvolvimento de uma área rural no estado de Sarawak na Malásia, cujo objetivo era o de utilizar os recursos naturais abundantes na região e transformá-la de um local rural em uma grande área industrial. Ainda segundo o autor, o planejamento contava com a construção de 52 usinas hidrelétricas para a geração de um potencial aproximado de $20.000 \mathrm{MW}$, em que uma parte dessas usinas iria desabrigar em torno de 30.000 a 50.000 indígenas da região, entretanto 
em momento algum, essas populações foram incluídas nos debates de tomadas de decisão na construção das usinas hidrelétricas. Por fim, Aeria (2016) destaca que a construção de usinas hidroelétricas causou um aumento do enriquecimento regional, no entanto, foi um enriquecimento que gerou frutos apenas para algumas pessoas envolvidas com o business de matriz energética renovável e não promoveu de fato um desenvolvimento econômico-social igualitário, o que ocasionou uma elitização da região.

\section{METODOLOGIA}

A presente pesquisa se classifica com um artigo de revisão sistemática, e esta possui o intuito de reunir a maior quantidade de possíveis estudos baseados em evidências já existentes com relevância para a investigação em curso, independentemente do seu local de publicação ou fundo disciplinar. Os princípios básicos por trás adoção de métodos de revisão sistemática são: transparência, clareza, foco, pesquisa unificada e comunidade praticante, igualdade, acessibilidade, ampla cobertura e síntese.

Para realizar os passos desta revisão sistemática ( $1^{\circ}$ estágio), foi escolhido o protocolo Thorpe, publicado em dezembro do ano de 2005, o qual irá guiar a todos os estágios desta pesquisa. Partindo-se desta revisão sistemática foram utilizados 23 descritores para realizar buscas na base de dados Scopus (Elsevier), sendo eles: agriculture, animal, autors, biodiversity, biota, community, construction, cultural heritage, extractivism, fauna, fish, fisheries, forest, institutions, Knowledge, lake, particip, resources, river, scale, science, technology and water, totalizando 117 arquivos dentre estes, artigos científicos, capítulos de livros e reportagens de revistas, conforme descreve a figura 3 , sendo organizados em planilha e divididos em abas classificadas como: referências, perguntas e temas.

Para os primeiros 57 arquivos ( $2^{\circ}$ estágio) utilizou-se como critério de exclusão os arquivos identificados como capítulos de livros ou reportagens, levando a exclusão de 2 arquivos. Logo após, para a realização de um primeiro filtro, partiu-se da pergunta geral "Qual é o estado da arte em Governança de Empreendimentos Hidrelétricos? “, e desta pergunta geral foram elaboradas 13 perguntas auxiliares como critério de classificação e relevância. Inicialmente foram lidos os resumos de todos os 55 artigos científicos identificados, na tentativa de responder cada uma destas perguntas auxiliares, ao final deste procedimento chegou-se a quantidade de 22 artigos que mais se destacaram e tiveram ligação de acordo com a maioria das perguntas auxiliares. 
Figura 3: Resumo do processo de revisão sistemática e seleção baseados no protocolo Thorpe.

\begin{tabular}{|c|c|c|c|}
\hline 1ํ ESTÁGIO & 2o ESTÁGIO & 3ํ ESTÁGIO & 4ํ ESTÁGIO \\
\hline \multicolumn{4}{|c|}{ ATIVIDADES } \\
\hline $\begin{array}{l}\text { Primeira seleção a } \\
\text { partir dos critérios } \\
\text { objetivos da revisão } \\
\text { sistemática. }\end{array}$ & $\begin{array}{l}\text { Critérios de exclusão pós } \\
\text { busca inicial dos arquivos } \\
\text { que não são classificados } \\
\text { como artigos científicos. }\end{array}$ & $\begin{array}{l}\text { Segunda seleção } \\
\text { (títulos/resumos) a } \\
\text { partir da análise de } \\
\text { título/resumo baseada } \\
\text { nos temas da } \\
\text { governança. }\end{array}$ & $\begin{array}{l}\text { Terceira seleção } \\
\text { aplicando outros } \\
\text { critérios objetivos } \\
\text { da revisão } \\
\text { sistemática } \\
\text { (pergunta de } \\
\text { pesquisa). }\end{array}$ \\
\hline \multicolumn{4}{|c|}{ RESULTADOS } \\
\hline $\begin{array}{l}\text { Base pesquisada: (1) } \\
\text { Descritores utilizados: } \\
\text { (23) } \\
\text { Arquivos encontrados: } \\
\text { (117) }\end{array}$ & $\begin{array}{l}\text { Arquivos duplicados: (0) } \\
\text { Capítulo de livro: (0) } \\
\text { Reportagem: (2) } \\
\text { Total de artigos: (115) }\end{array}$ & $\begin{array}{l}\text { Artigos selecionados pelo } \\
\text { critério } \\
\text { "perguntas/respostas": } \\
(22) \\
\text { Artigos selecionados } \\
\text { pelo critério "temas": } \\
(22) \\
\text { Total de artigos: (44) }\end{array}$ & $\begin{array}{l}\text { Total de artigos } \\
\text { selecionados pós } \\
\text { segundo filtro: } \\
\text { (20) }\end{array}$ \\
\hline
\end{tabular}

Fonte: Adaptado de Thorpe et al. (2005, p.259).

Após esta filtragem inicial, o procedimento utilizado para os 60 arquivos restantes $\left(2^{\circ}\right.$ estágio), foi realizado inicialmente o mesmo procedimento anterior, com o mesmo critério para exclusão, porém não houve nenhuma exclusão, associado a um sistema de avaliação proposto pelos autores. Este foi construído da seguinte maneira: primeiro contabilizou-se a quantidade de temas que cada artigo abordava, com a seguinte especificação para cada tema: 1 . Unidades de estrutura dos problemas; 2. Recursos em disputa e seus conflitos; 3. Instituições; 4. Escalas; 5. Conhecimento e Saberes; 6. Atores; 7. Custos e benefícios. Em sequência, foi realizada uma primeira leitura, para qualificar a relevância dos mesmos em relação ao que foi proposto pelos autores como objetivo deste artigo. A partir deste sistema de avaliação, cada artigo recebeu uma nota entre 0 e 10 , em que aqueles que obtiveram as notas superiores a 6 foram escolhidos. Assim, dos 60 documentos, restaram 22 artigos.

Passado o primeiro filtro, realizado em duas etapas, dos 115 arquivos resultantes da pesquisa inicial foram selecionados 44 artigos científicos ( $3^{\circ}$ estágio). Como última filtragem ( $4^{\circ}$ estágio), fora realizada uma leitura mais minuciosa dos artigos selecionados, com intuito de obter aqueles que de fato iriam ao encontro de explanar a pergunta de pesquisa. Desta maneira, para a realização deste trabalho foram definidos a quantidade de 20 artigos científicos. 
A definição de resultados e discussão será embasada a partir do aporte teórico de análise a governança do risco considerando os seguintes atributos: pré-avaliação (identificação e enquadramento), avaliação (causas e consequências técnicas), caracterização e avaliação (julgamento e necessidade de gerenciar o risco), além dos aspectos transversais (comunicação e envolvimento das partes interessadas), conforme descreve o framework do IRGC.

Este framework é uma ferramenta importante para esta análise, pois, possui uma estrutura que orienta para a identificação e o manuseio antecipado de riscos, envolvendo várias partes interessadas além de recomendar uma abordagem inclusiva para estruturar, avaliar, gerenciar e comunicar importantes questões de risco, muitas vezes marcadas por complexidade, incerteza e ambiguidade.

\section{RESULTADOS E DISCUSSÕES}

Faria et. al. (2017) após realizarem estudo sobre impactos socioeconômicos locais durante o período de construção de 56 usinas hidrelétricas brasileiras realizadas entre os anos de 1991 a 2010 concluíram que, existe a falta de estudos quantitativos que analisam os riscos por longos períodos, somados a falta de estudos que incluam este tipo de projeto no contexto de um país em desenvolvimento. Estas construções resultam em um boom de curto prazo e um fluxo de atividade econômica de longo prazo para os municípios vizinhos das usinas hidrelétricas, porém com pequenas e raras melhorias nas condições socioeconômicas.

No Brasil uma comunidade que sofre consequências diretas são os pescadores ribeirinhos. Doria et. al. (2017) pesquisaram sobre a invisibilidade da pesca e a inadequação da participação dos pescadores no processo de desenvolvimento de energia hidrelétrica na Amazônia, com ênfase nas lacunas entre resultados reais e obrigatórios por lei. Foram identificadas deficiências no processo de licenciamento de barragens, lacunas críticas de dados, participação inadequada das partes interessadas, violação de direitos humanos, negligência do conhecimento dos pescadores, falta de organização e representação por grupos de pescadores e falta de estrutura e capacidade governamental para gerenciar as atividades de construção de barragens ou apoiar os pescadores após a construção. Os pescadores relataram, nas entrevistas, que geralmente foram marginalizados ou excluídos da tomada de decisões em relação ao planejamento, construção, mitigação, compensação e monitoramento dos riscos e impactos socioecológicos originados pelas construções. Mesmo com a existência de políticas e leis nacionais e internacionais que exigem a participação das comunidades 
afetadas no processo de licenciamento ambiental, em geral, essas políticas são ignoradas, deixando as comunidades locais sem poder.

Corroborando com este pensamento, Piaia e Cervi (2017) concluem em sua pesquisa que os conflitos socioambientais gerados pelos projetos hidrelétricos brasileiros mais recentes mostram que os meios tradicionais de discussão, como as audiências públicas realizadas durante a fase de licenciamento ambiental, não são suficientes para conciliar os diversos interesses. Em sua pesquisa ambos demonstraram (in) sustentabilidade socioambiental do planejamento energético brasileiro, destacando os significativos impactos socioambientais das usinas hidrelétricas, a deficiência na implementação dos instrumentos da Política Nacional do Meio Ambiente e o estudo prévio de impactos ambientais, que levaram à ocorrência de danos ambientais irreversíveis e inúmeros conflitos socioambientais, agravados pela falta de acesso à informação, falta de participação e políticas públicas com finalidade para realocação das populações afetadas na região do rio Xingu durante a construção da usina hidrelétrica de Belo Monte, no município de Altamira/PA.

Outro fator que ganha atenção em relação aos riscos locais em construções de usinas hidrelétricas são os impactos de gênero. Em pesquisa realizada na região do Laos e Vietnã, Hill et. al. (2017) estudaram os efeitos para milhões de pessoas que, através da bacia do rio Mekong, utilizam recursos hídricos como meio de subsistência e segurança alimentar, além de ser um aspecto importante quanto a cultura e vida religiosa destes habitantes. Devido a este cenário as mulheres desempenham um papel importante no uso e gerenciamento da água em suas famílias pois cabem a elas a função de coleta e transporte de água para a casa, limpeza e lavagem na margem do rio, além de participarem de atividades agrícolas que dependem da água, no entanto, nestes países, as mulheres têm sido marginalizadas quanto a oportunidade de voz para a tomada de decisão sobre as questões da água.

Os povos indígenas também sentem na pele estes impactos, Cooke et al. (2017) analisam uma estrutura de justiça ambiental estendida para entender os esquemas de reassentamento e compensação para os povos indígenas para a construção da barragem de Bakun em Bornéu, Malásia Oriental, analisando as medidas de proteção social projetadas para a proteção dos povos indígenas e seus meios de subsistência. Os autores concluem que as políticas de proteção social não protegiam de forma eficaz os povos indígenas e suas terras, mas facilitavam um processo de mercantilização de terras e pessoas. Uma das áreas problemáticas dessa política de modernização é remover os laços entre os povos indígenas e suas terras ancestrais, onde o papel dos povos indígenas em relação às suas terras ancestrais de um lado, e as elites locais, nacionais e internacionais em escala global, colidem no caso de barragens 


\section{ARTIGO}

INOVAÇÃo

hidrelétricas, ficando claro a existência da falta de interesse em respeitar as necessidades e os direitos históricos dos povos indígenas em nome dos interesses do Estado-nação.

No mesmo cenário asiático, um outro estudo explora as relações entre povos ribeirinhos e estados nos projetos hidrelétricos da região rio Mekong. $\mathrm{O}$ aumento da demanda doméstica por energia elétrica, levaram os governos do Vietnã e do Camboja a iniciar projetos ao longo do rio Sesan, principal afluente do rio Mekong. Ambos os governos anunciaram em campanhas publicitárias que os projetos hidrelétricos proporcionariam benefícios como eletricidade e oportunidades de emprego, os quais elevarão os padrões de vida e reduziriam a pobreza. Porém não houve convites aos habitantes do rio Sesan para participar dos processos de tomada de decisão em torno do desenvolvimento das barragens hidrelétricas. Mesmo alcançando alguns benefícios, esses habitantes foram deixados com muitas repercussões sociais e ambientais rastreáveis à construção e operação das barragens. É possível afirmar que os projetos hidrelétricos são orientados para a segurança humana. No entanto, a ausência de participação do povo ribeirinho nos projetos de desenvolvimento de energia hidrelétrica é um sinal convincente de que os projetos raramente capacitam as pessoas (CHU, 2017).

Ainda no cenário vietnamita, Luu, Meding e Kanjanabootra (2017), enfatizam a prioridade no desenvolvimento de investimentos que tragam resultados imediatos, em detrimento da realização de estratégias que visam diminuir os riscos de desastres. Ainda segundo os autores, a fragilidade do planejamento e gerenciamento no desenvolvimento de usinas hidrelétricas podem levar a riscos de inundação na região central do Vietnã, país onde $71,4 \%$ da população vive sob o risco de desastres. Dentre as fragilidades, Hai, Gobin e Hens (2016), apontam a falta da participação dos stakeholders locais na fase de planejamento, como na elaboração de indicadores de desenvolvimento sustentável, bem como na tomada de decisões.

No caso indiano, Jumani et al. (2017), também indicam a existência de uma lacuna na comunicação entre os responsáveis na construção de usinas hidrelétricas de pequeno porte e os habitantes locais. $\mathrm{O}$ autor evidencia essa lacuna por meio dos resultados obtidos na pesquisa realizada junto as comunidades afetadas pela construção das usinas, em que $100 \%$ dos participantes dizem que as autoridades relevantes não forneceram informações de conscientização e não procuraram os locais para tratar das preocupações da região.

No Nepal, segundo Koirala, Hill e Morgan (2017), a constituição garante o acesso à informação como direito fundamental de seus cidadãos. Ainda de acordo com os autores, a World Commission on Dams (WCD) afirma que as comunidades locais que podem ser afetadas pela construção de usinas hidrelétricas, devem receber uma gama de informações dos projetos 
propostos, de maneira compreensível pela população afetada. Entretanto, os autores abordam que tais garantias não foram colocadas em prática nesse país, onde os habitantes locais receberam apenas algumas informações limitadas a respeito do projeto e em linguagem não compreensível pela população, visto o alto índice de analfabetismo. A lacuna de comunicação entre as autoridades responsáveis e a comunidade local, também é evidenciada quando os autores compartilham as experiências da população local, em que relatam as passagens rápidas dos líderes políticos, com discursos vagos para uma minoria de líderes locais e sem abertura para diálogo com a população.

No contexto chinês, Rousseau (2017) aborda que o estado chinês tende a promover um desenvolvimento econômico estruturalista, o qual peca em analisar as complexidades nas regiões de subsistência. $\mathrm{O}$ autor afirma que esse desenvolvimento no cenário da construção de hidrelétricas é voltado para as províncias ricas do leste chinês, onde a maioria das demandas de mercado existem, em detrimento das regiões economicamente mais frágeis. Segundo o autor, cinco grandes conglomerados dominam o mercado de geração de energia nesse país, de modo que o governo chinês acaba por tomar medidas mais severas e com menos tolerância ao debate público sobre os possíveis impactos nas regiões afetadas, assim evidenciando um desequilíbrio de poder entre as partes interessadas nas construções das usinas. Como exemplo, Rousseau (2017) cita os critérios utilizados pelas autoridades para a determinação de compensação pelas terras inundadas dos moradores, dentre elas a indenização financeira, em que segundo o autor, 95\% dos participantes da pesquisa disseram que jamais venderiam suas terras. Esse alto número se deve ao fato da ligação vital que o povo analisado (Handai) possui com suas terras, outro fator que foi negligenciado pelos interessados na construção das usinas. Por fim, Rousseau (2017) afirma que, apesar das diretrizes do Mecanismo de Desenvolvimento Limpo (MDL) do Protocolo de Kyoto, exigir que os desenvolvedores dos projetos sejam submetidos a consultas pelos stakeholders locais, não houve abertura ao povo Handai de compartilhar suas experiências, expectativas e preocupações a respeito da construção da barragem de Madushan.

Quanto a política externa chinesa na construção de usinas hidrelétricas, é importante ressaltar o comportamento adaptável que o país utiliza, de acordo com a região em que se é realizada a intervenção. Freeman (2017), aborda essa adaptabilidade chinesa em duas situações, uma em Mianmar e outra no Paquistão. No primeiro caso, a autora trata a respeito do projeto da usina de Myistone, o qual possuía análises robustas de impactos na fauna terrestre, mas com problemas metodológicos e um descaso nos impactos sociais, inclusive com falhas na participação pública. Ainda segundo a autora, apesar de alguns protestos dos líderes Kachins locais, a construção da usina entrou em processo. Entretanto, conforme Freeman (2017), quando 


\section{ARTIGO}

: INOVAÇÃo

o país que recebe a intervenção chinesa eleva seus padrões de exigência de impactos sociais e ambientais, a China demonstra uma entrega melhor de seus projetos. A autora cita o caso paquistanês, em que um projeto foi escolhido em 2006 e apenas após diversas análises rigorosos é que teve sua aprovação concluída em 2015. Durante esse período, o projeto passou por avaliações de empresas locais e de uma consultora alemã, além de ter tido participação da população local por meio de uma série de audiências públicas.

Kurdoglu (2016), aborda a questão turca, em que com o objetivo de sanar as demandas de energia elétrica no país, o rápido desenvolvimento de usinas de energia hidrelétrica tem causado impactos sociais e ambientais negativos. Segundo o autor, especialistas nas análises de estudos de impactos ambientais, apontam que os realizados na Turquia não possuem aplicações legais e técnicas, falham nas análises ecológicas e sociais, além de serem preparados apenas por motivações financeiras. Assim, os desenhos, planejamentos e aplicações para a construção de projetos de investimentos na Turquia, não levam em consideração a participação popular e as questões sociais (KURDOGLU, 2016). 
Quadro 2 - Elementos de governança do risco identificados nos artigos analisados.

\begin{tabular}{|c|c|c|c|c|c|}
\hline & $\begin{array}{l}\text { Pré- } \\
\text { avaliação }\end{array}$ & Avaliação & $\begin{array}{l}\text { Caracterização } \\
\text { e avaliação }\end{array}$ & Gerenciamento & \begin{tabular}{|l|} 
Aspectos \\
Transversais
\end{tabular} \\
\hline ID01 & Observado & $\begin{array}{l}\text { Não foi } \\
\text { observado }\end{array}$ & $\begin{array}{l}\text { Não foi } \\
\text { observado }\end{array}$ & Observado & Inexistente \\
\hline ID02 & Observado & $\begin{array}{l}\text { Não foi } \\
\text { observado }\end{array}$ & $\begin{array}{l}\text { Não foi } \\
\text { observado }\end{array}$ & Observado & Fraco \\
\hline ID03 & Observado & $\begin{array}{l}\text { Não foi } \\
\text { observado }\end{array}$ & Observado & Observado & Fraco \\
\hline ID04 & Observado & $\begin{array}{l}\text { Não foi } \\
\text { observado }\end{array}$ & $\begin{array}{l}\text { Não foi } \\
\text { observado }\end{array}$ & $\begin{array}{l}\text { Não foi } \\
\text { observado }\end{array}$ & Inexistente \\
\hline ID05 & Observado & Observado & $\begin{array}{l}\text { Não foi } \\
\text { observado }\end{array}$ & $\begin{array}{l}\text { Não foi } \\
\text { observado }\end{array}$ & Fraco \\
\hline ID06 & Observado & $\begin{array}{l}\text { Não foi } \\
\text { observado }\end{array}$ & $\begin{array}{l}\text { Não foi } \\
\text { observado }\end{array}$ & $\begin{array}{l}\text { Não foi } \\
\text { observado }\end{array}$ & Fraco \\
\hline ID07 & Observado & $\begin{array}{l}\text { Não foi } \\
\text { observado }\end{array}$ & $\begin{array}{l}\text { Não foi } \\
\text { observado }\end{array}$ & $\begin{array}{l}\text { Não foi } \\
\text { observado }\end{array}$ & Fraco \\
\hline ID08 & Observado & Observado & Observado & Observado & Fraco \\
\hline ID09 & Observado & $\begin{array}{l}\text { Não foi } \\
\text { observado }\end{array}$ & $\begin{array}{l}\text { Não foi } \\
\text { observado }\end{array}$ & $\begin{array}{l}\text { Não foi } \\
\text { observado }\end{array}$ & Fraco \\
\hline ID10 & Observado & Observado & $\begin{array}{l}\text { Não foi } \\
\text { observado }\end{array}$ & $\begin{array}{l}\text { Não foi } \\
\text { observado }\end{array}$ & Fraco \\
\hline ID11 & Observado & Observado & $\begin{array}{l}\text { Não foi } \\
\text { observado }\end{array}$ & $\begin{array}{l}\text { Não foi } \\
\text { observado }\end{array}$ & Inexistente \\
\hline ID12 & Observado & Observado & $\begin{array}{l}\text { Não foi } \\
\text { observado }\end{array}$ & $\begin{array}{l}\text { Não foi } \\
\text { observado }\end{array}$ & Inexistente \\
\hline ID13 & Observado & Observado & Observado & $\begin{array}{l}\text { Não foi } \\
\text { observado }\end{array}$ & Fraco \\
\hline ID14 & Observado & Observado & $\begin{array}{l}\text { Não foi } \\
\text { observado }\end{array}$ & $\begin{array}{l}\text { Não foi } \\
\text { observado }\end{array}$ & Inexistente \\
\hline ID15 & Observado & Observado & $\begin{array}{l}\text { Não foi } \\
\text { observado }\end{array}$ & $\begin{array}{l}\text { Não foi } \\
\text { observado }\end{array}$ & Fraco \\
\hline ID16 & Observado & Observado & $\begin{array}{l}\text { Não foi } \\
\text { observado }\end{array}$ & $\begin{array}{l}\text { Não foi } \\
\text { observado }\end{array}$ & Inexistente \\
\hline ID17 & Observado & Observado & Observado & Observado & Forte \\
\hline ID18 & Observado & Observado & $\begin{array}{l}\text { Não foi } \\
\text { observado }\end{array}$ & $\begin{array}{l}\text { Não foi } \\
\text { observado }\end{array}$ & Fraco \\
\hline ID19 & Observado & Observado & $\begin{array}{l}\text { Não foi } \\
\text { observado }\end{array}$ & $\begin{array}{l}\text { Não foi } \\
\text { observado }\end{array}$ & Inexistente \\
\hline ID20 & Observado & Observado & Observado & $\begin{array}{l}\text { Não foi } \\
\text { observado }\end{array}$ & Fraco \\
\hline
\end{tabular}

Fonte: Dados da pesquisa.

Nalepa, Gianotti e Bauer (2016), abordam o caso etíope, em que com o objetivo do crescimento de geração de energia elétrica para exportação aos países vizinhos, a Etiópia 
realizou a separação das terras federais em dois tipos, as "férteis", que possuem potencial para a agricultura, enquanto as "não-utilizáveis" foram consideradas "marginais", sem potencial para desenvolvimento econômico. Entretanto, as autoras apontam que mais de $23 \%$ dessas terras "não-utilizáveis" são usadas para o pastoreio e o agro pastoreio, em que impactam em torno de 10 milhões de etíopes que vivem deste meio de sustento.

Siciliano e Urban (2017), realizaram um compilado das entrevistas realizadas junto aos moradores locais impactados pelas construções das usinas de Bui, em Gana; Bakun, na Malásia; e Kamchay, no Camboja. Os autores realizaram entrevistas junto à população local, com objetivo de se obter a visão desses, sobre o acesso antes e depois dos seguintes recursos: terra, produtos florestais, comida, água e energia. Os resultados obtidos pelos autores podem ser resumidos em, após a construção as usinas, uma diminuição ao acesso dos recursos naturais, com perdas e escassez de terra; não obtenção de produtos florestais, como frutos e plantas medicinais; redução na obtenção de comida; distanciamento dos rios, o que causou uma diminuição da pesca e o acesso a água; e como único fator positivo, acesso à energia elétrica por todos os moradores da região de Bui e Bakun, enquanto apenas alguns nas proximidades de Kamchay.

O quadro 2 indica quais elementos e aspectos transversais do framework foram identificados nos artigos selecionados para a revisão. Na coluna à esquerda estão os identificadores dos artigos, enquanto na linha superior os elementos/aspectos analisados. As avaliações foram atribuídas como: não foi observado e observado para a categorias elementos e inexistente, fraco e forte para a categoria aspectos transversais.

Quanto a análise através dos dados do quadro 2, quanto a verificação aos elementos de forma individual, nota-se que o primeiro elemento (pré-avaliação) está presente em $100 \%$ dos estudos, mas por mera formalidade ou por uma tentativa de legalizar o início do projeto para conseguir autorização e dar início a construção das usinas, uma vez que o próprio Banco Mundial, maior financiador identificado, exige um estudo prévio sobre impactos e riscos futuros resultantes destes projetos.

O segundo elemento (avaliação) foi observado em 60\% dos artigos, esta queda nas observações pode estar vinculada ao fato de que após a fase de autorização para construção das usinas há um desinteresse por parte dos desenvolvedores dos projetos em prosseguir com as identificações e avaliações dos riscos.

Vindo em uma proporção decrescente, nota-se que os elementos 3 (caracterização e avaliação) e 4 (gerenciamento) foram observados em $25 \%$ dos artigos, isto pode ser justificado pela possível existência de uma relação entre o desinteresse no aprofundamento e detalhamento 
das análises dos riscos com a complexidade de gerenciamento de cada situação, visto que neste momento percebe-se uma omissão em relação a responsabilidade social dos atores responsáveis pelo desenvolvimento e implantação do projeto.

Quanto aos aspectos transversais conclui-se que em 95\% dos artigos obteve-se a classificação como "inexistente" ou "fraca", onde a comunicação aberta, transparente e inclusiva entre as partes interessadas foi desconsiderada. Isso se deve ao não cumprimento de todos os elementos propostos pelo framework, visto que para o seu sucesso todos os elementos devem estar presentes e interligados de maneira eficiente para dar apoio as decisões a serem tomadas quanto a contextos sociais.

\section{CONSIDERAÇÕES FINAIS}

Este estudo tem como objetivo compreender os mecanismos da governança do risco nas construções de usinas hidrelétricas visando a preservação ambiental por estas, após análise de revisão sistemática de 20 artigos selecionados, principalmente no que tange aos parâmetros de risco elencados no framework elaborado pela IRGC, selecionado para esta comparação. Estes artigos continham pesquisas realizadas em diversos países como Brasil, Camboja, China, Etiópia, Gana, Índia, Laos, Malásia, Nepal, Paquistão, Turquia e Vietnã.

O presente estudo sob a lente da governança do risco, observa que existe uma preocupação inicial na identificação e avaliação de riscos vinculados a construção de usinas hidrelétricas apenas com o objetivo de sanar as demandas de aprovação dos projetos propostos. Assim, percebe-se que após esta etapa os riscos vinculados aos impactos sociais são desconsiderados ao passo que apenas os riscos econômico-financeiros são analisados com afinco. Ao longo do desenvolvimento do projeto e da efetiva construção das usinas esta lacuna entre o social e o financeiro se agrava.

Entretanto quando há um posicionamento mais exigente por parte dos governos locais em relação aos impactos e riscos que podem afetar as populações locais; as partes interessadas no desenvolvimento e implementação do projeto entregam produtos com maior qualidade mitigando os impactos inevitáveis, assim como no caso paquistanês, que foi o único projeto, em que todos os quatro elementos foram observados, além de um forte aspecto transversal.

Portanto, para o sucesso da governança do risco, é importante considerar os atores envolvidos nas áreas de risco e seu conhecimento, possibilitando a discussão dos riscos associados às barragens e o envolvimento direto da sociedade na identificação, avaliação, gestão e comunicação dos riscos. O que remete para um aprofundamento em outras pesquisas 


\section{ARTIGO}

Z INOVAÇÃO

sobre o tema, com dados empíricos e que pode ser realizada em Usinas Hidrelétricas do Complexo do Madeira em Rondônia, visando subsidiar a normalização de futuros projetos hidrelétricos no Brasil. 


\section{REFERÊNCIAS}

AERIA, A. Economic Development via Dam Building: The Role of the State Government in the Sarawak Corridor of Renewable Energy and the Impact on Environment and Local Communities. Southeast Asian Studies, [s. 1.], v. 5, n. 3, p. 373-412, 2016. Disponível em: https://www.jstage.jst.go.jp/article/seas/5/3/5_373/_article.

ASHFORD, N.; REST, K. Public participation in contaminated communities. 1999. Disponível em: https://ashford.mit.edu/public-participation-contaminated-communities.

BEVIR, M. Governance: a very short introduction. Oxford: Oxford University Press, 2012.

CHU, T.-W. Riparians versus the State in Southeast Asia. Asian Survey, [s. 1.], v. 57, n. 6, p. 1086-1109, 2017. Disponível em:

https://online.ucpress.edu/as/article/57/6/1086/24984/Riparians-versus-the-State-in-SoutheastAsiaHuman.

COOKE, F. M. et al. The Limits of Social Protection: The Case of Hydropower Dams and Indigenous Peoples' Land. Asia \& the Pacific Policy Studies, [s. 1.], v. 4, n. 3, p. 437-450, 2017. Disponível em: http://doi.wiley.com/10.1002/app5.187.

DAGNINO, E.; OLVERA, A.; PANFICHI, A. A disputa pela Construção Democrática na América Latina. São Paulo: Paz e Terra. 2006.

DE FARIA, F. A. M. et al. The local socio-economic impacts of large hydropower plant development in a developing country. Energy Economics, [s. 1.], v. 67, p. 533-544, 2017. Disponível em: https://doi.org/10.1016/j.eneco.2017.08.025.

DE MARCHI, B.; SCOLOBIG, A. "Experts and Residents Views on Social Vulnerability to Flash Floods in na Alpine Region”. 2012. Disasters 36 (2): 316-337. DOI 10.1111/j.14677717.2011.01252.x

DI GIULIO, G. M.; FERREIRA, L. D. C. Governança do risco: uma proposta para lidar com riscos ambientais no nível local. Desenvolvimento e Meio Ambiente, [s. 1.], v. 28, n. VI, p. 29-39, 2013. Disponível em: http://revistas.ufpr.br/made/article/view/30171.

DORIA, C. R. da C. et al. The invisibility of fisheries in the process of hydropower development across the Amazon. Ambio, [s. 1.], v. 47, n. 4, p. 453-465, 2018. Disponível em: https://doi.org/10.1007/s13280-017-0994-7.

ELKINGTON, J. Enter the triple bottom line. In: HENRIQUES, A.; RICHARDSON, J. (Eds.). The Triple Bottom Line: Does it All Add Up. Londres: Routledge, 2013. p. 1-16.

FREEMAN, C. P. Dam diplomacy? China's new neighbourhood policy and Chinese dambuilding companies. Water International, [s. 1.], v. 42, n. 2, p. 187-206, 2017. Disponível em: http://dx.doi.org/10.1080/02508060.2017.1276040.

GUIMARÃES, N. A.; MARTIN, S. Competitividade e desenvolvimento: atores e instituições locais. São Paulo: Ed. Senac, 2001.

HAI, L. T.; GOBIN, A.; HENS, L. Select indicators and prioritize solutions for desertification and drought in Binh Thuan, Vietnam. Chinese Journal of Population Resources and 
Environment, [s. 1.], v. 14, n. 2, p. 123-132, 2016. Disponível em: http://dx.doi.org/10.1080/10042857.2016.1177315.

HILL, C. et al. Lessons learnt from gender impact assessments of hydropower projects in Laos and Vietnam. Gender \& Development, [s. 1.], v. 25, n. 3, p. 455-470, 2017. Disponível em: https://www.tandfonline.com/doi/full/10.1080/13552074.2017.1379777.

HOHENSINNER, S.; JUNGWIRTH, M.; MUHAR, S.; HABERSACK, H. Historical analyses: A foundation for developing and evaluating river-type specific restoration programs. International Journal of River Basin Management, vol. 3, no. 2, p. 87-96, Jun. 2005. DOI 10.1080/15715124.2005.9635248.

HOLAHAN, R.; LUBELL, M.; Collective action theory. Handbook on Theories of Governance. [S. l.]: Edward Elgar Publishing, [s. d.]. p. 21-31. 2016. DOI $10.4337 / 9781782548508.00010$.

INTERNATIONAL ATOMIC ENERGY AGENCY. Nuclear Power Reactors in the World: 2018 edition. Viena: IAEA, 2018. Disponível em:

https://www.iaea.org/publications/13379/nuclear-power-reactors-in-the-world.

INTERNATIONAL RISK GOVERNANCE COUNCIL (IRGC). Risk Governance Framework. 2012. Available at: https://irgc.org/risk-governance/irgc-risk-governanceframework/.

JASANOFF, S.; MARTELLO, M. L.; EARTHLY POLITICS: LOCAL AND GLOBAL IN ENVIRONMENTAL GOVERNANCE. Choice Reviews Online, vol. 42, no. 09, p. 42-551142-5511, 1 May 2004. DOI 10.5860/CHOICE.42-5511.

JUMANI, S.; RAO, S.; MACHADO, S.; PRAKASH, A. Big concerns with small projects: Evaluating the socio-ecological impacts of small hydropower projects in India. Ambio, vol. 46, no. 4, p. 500-511, 10 May 2017. DOI 10.1007/s13280-016-0855-9.

KIM, K.; PARK, H.; KIM, H. Real options analysis for renewable energy investment decisions in developing countries. Renewable and Sustainable Energy Reviews, vol. 75, p. 918-926, Aug. 2017. DOI 10.1016/j.rser.2016.11.073.

KOIRALA, S.; HILL, D.; MORGAN, R. Impacts of the delay in construction of a large scale hydropower project on potential displacees. Impact Assessment and Project Appraisal, [s. 1.], v. 35, n. 1, p. 106-116, 2017. Disponível em:

http://dx.doi.org/10.1080/14615517.2016.1271540.

KURDOGLU, O. Expert-based evaluation of the impacts of hydropower plant construction on natural systems in Turkey. Energy \& Environment, [s. 1.], v. 27, n. 6-7, p. 690-703, 2016. Disponível em: http://journals.sagepub.com/doi/10.1177/0958305X16667186.

LOUZADA, A. F.; RAVENA, N. Dam safety and risk governance for hydroelectric power plants in the Amazon. Journal of Risk Research, [s. 1.], v. 22, n. 12, p. 1571-1585, 2019. Disponível em: https://doi.org/10.1080/13669877.2018.1501595.

LUU, C.; VON MEDING, J.; KANJANABOOTRA, S. Balancing costs and benefits in Vietnam's hydropower industry: a strategic proposal. International Journal of Disaster 
Resilience in the Built Environment, [s. 1.], v. 8, n. 1, p. 27-39, 2017. Disponível em: https://www.emerald.com/insight/content/doi/10.1108/IJDRBE-05-2016-0018/full/html.

NALEPA, R. A.; SHORT GIANOTTI, A. G.; BAUER, D. M. Marginal land and the global land rush: A spatial exploration of contested lands and state-directed development in contemporary Ethiopia. Geoforum, vol. 82, p. 237-251, Jun. 2017. DOI 10.1016/j.geoforum.2016.10.008.

PIAIA, T. C.; CERVI, J. R. Belo Monte, its dystopia, and the (in) social and environmental sustainability of brazilian energy planning. Veredas do Direito: Direito Ambiental e Desenvolvimento Sustentável, [s. 1.], v. 14, n. 30, p. 169-186, 2017. Disponível em: revista.domhelder.edu.br/index.php/veredas\%0D.

REN21. Renewables 2019 Global Status Report. REN21 Secretariat; Paris, França, 2019. Disponível em: https://www.ren21.net/reports/global-status-report/.

RENN, O. Risk governance: Coping with uncertainty in a complex world. [S. l.: s. n.], 2008. DOI 10.4324/9781849772440.

RENN, O. Systemic Risks: The New Kid on the Block. Environment: Science and Policy for Sustainable Development, [s. 1.], v. 58, n. 2, p. 26-36, 2016. Disponível em: http://www.tandfonline.com/doi/full/10.1080/00139157.2016.1134019.

RENN, O.; WALKER, K. D. (Eds.). Global Risk Governance. Dordrecht: Springer Netherlands, 2008. vol. 1, (International Risk Governance Council Bookseries). DOI 10.1007/978-1-4020-6799-0.

RHODES, R. A. W. The New Governance: Governing without Government. Political Studies, vol. 44, no. 4, p. 652-667, 29 Sep. 1996. DOI 10.1111/j.1467-9248.1996.tb01747.x.

ROUSSEAU, J.-F. Does carbon finance make a sustainable difference? Hydropower expansion and livelihood trade-offs in the Red River valley, Yunnan Province, China. Singapore Journal of Tropical Geography, vol. 38, no. 1, p. 90-107, Jan. 2017. DOI 10.1111/sjtg.12176.

SICILIANO, G.; URBAN, F. Equity-based Natural Resource Allocation for Infrastructure Development: Evidence From Large Hydropower Dams in Africa and Asia. Ecological Economics, [s. 1.], v. 134, p. 130-139, 2017. Disponível em: https://linkinghub.elsevier.com/retrieve/pii/S092180091630372X.

THORPE, R.; HOLT, R.; MACPHERSON, A.; PITTAWAY, L. Using knowledge within small and medium-sized firms: A systematic review of the evidence. International Journal of Management Reviews, vol. 7, no. 4, p. 257-281, Dec. 2005. DOI 10.1111/j.14682370.2005.00116.x.

VAN ASSELT, M.; O. RENN. 2011. Risk Governance. Journal of Risk Research 14 (4): 431-449. DOI 10.1080/13669877.2011.553730.

VIEIRA, J. B.; BARRETO, R. T. S. Governança, gestão de riscos e integridade. Brasília: Enap, 2019. Disponível em:

https://repositorio.enap.gov.br/bitstream/1/4281/1/5_Livro_Governança Gestão de Riscos e Integridade.pdf 